\title{
GERMINAÇÃo E VIGOR DE SEMENTES DE MARACUJÁ AMARELO SOB ESTRESSE SALINO
}

\author{
Paula Aparecida Muniz de Lima' ${ }^{1}$ utor $^{1}$ \\ Khétrin Silva Maciel $^{2}$ \\ Rodrigo Sobreira Alexandre ${ }^{3}$ \\ José Carlos Lopes ${ }^{4}$
}

Resumo: Objetivou-se com o presente trabalho estudar a qualidade fisiológica de sementes de maracujá amarelo submetidas ao estresse salino. Foram utilizadas sementes de maracujás colhidas em pomares da região Sul capixaba. A germinação das sementes foi feita em rolos de papel germitest, colocados em câmaras de germinação tipo $B O D$, à temperatura de $20-30^{\circ} \mathrm{C}$. Foi avaliado o estresse salino em soluções de cloreto de potássio e cloreto de sódio, com potenciais osmóticos de 0,0; -0,4; -0,8; -1,2; -1,6 e -2,0 MPa. O delineamento experimental foi inteiramente ao acaso, com quatro repetições de 25 sementes por tratamento. Foram analisadas a germinação e o vigor pelo índice de velocidade de germinação das sementes. A germinação e o vigor foram afetados à medida que os potencias osmóticos tornaram-se mais negativo, inibindo totalmente a germinação quando a concentração de sal foi maior, ou seja, -1,2 MPa.

Palavras-chave: Cloreto de potássio; Cloreto de sódio; Passiflora edulis Sims f. flavicarpa D.; Potenciais osmóticos.

\footnotetext{
${ }^{1}$ Agronomia/Universidade Federal do Espírito Santo, Brasil. E-mail: aluap-lima@hotmail.com.

2 Agronomia/Universidade Federal do Espírito Santo, Brasil. E-mail: khetrinmaciel@gmail.com.

${ }^{3}$ Agronomia/Universidade Federal do Espírito Santo, Brasil. E-mail: rodrigosobreiraalexandre@gmail.com.

${ }^{4}$ Agronomia/Universidade Federal do Espírito Santo, Brasil. E-mail: jcufes@bol.com.br.
} 